\title{
A promising natural purple batter system with antioxidant activity for vacuum fried breaded shrimp
}

\author{
Jiayin XU ${ }^{1}\left(\mathbb{C}\right.$, Hongwu JI ${ }^{1,2,3,4 *}$, Hang DONG ${ }^{1}$, Shaoqi DUAN ${ }^{1}$, Hao $\mathrm{CHEN}^{1}$, Di ZHANG ${ }^{1}$, Shucheng LIU $^{1,2,3,4,5}$, \\ Weijie $\mathrm{MAO}^{1,2,3,4,5}$
}

\begin{abstract}
This study aims to develop a batter system with natural purple and functional quality for vacuum fried breaded shrimp. Purple sweet potato flour (PSPF), soy protein isolate (SPI), and xanthan gum were used as coating materials. The effect of the ratio of SPI and xanthan gum on the rheological properties, coating pick-up, color, moisture content, oil content, texture, anthocyanin content and antioxidant activity were investigated. Compared with the control group, it was observed that the batter system with PSPF, SPI and xanthan gum had better rheological properties. The result showed that a ratio of 2:1 for SPI to xanthan gum had the highest coating pick-up value $(49.83 \%)$, the more attractive purple $\left(a^{*}=3.07\right)$, less oil content $(20.55 \%)$ and retained higher anthocyanin content $(51.71 \mathrm{mg} / 100 \mathrm{~g})$. Based on the results of anthocyanin content, vacuum fried shrimps were analyzed for antioxidant activity. In the 2,2-diphenyl-1-picrylhydrazyl $(\bullet \mathrm{DPPH})$, hydroxyl $(\bullet \mathrm{OH})$ radical-scavenging assay test, PSPF vacuum fried shrimps showed high free-radical scavenging activity (60.19\% for •DPPH and $35.97 \%$ for $\bullet \mathrm{OH})$. Therefore, the batter system with PSPF, SPI and xanthan gum is a promising coating material, which is widely used for vacuum fried breaded products, such as pork chop, steak, chicken nuggets and fish fingers.
\end{abstract}

Keywords: vacuum frying; purple batter system; breaded shrimp; rheological properties; anthocyanin content; antioxidant activity.

Practical Application: Development of a batter system with PSPF, SPI and xanthan gum for vacuum fried products with natural purple and better functional qualities.

\section{Introduction}

Over recent years, with the development of the economy, fast foods, especially fried breaded food products, are globally appreciated due to the improvement of the flavor, texture and appearance of food products (Surojanametakul et al., 2020). At present, fried breaded foods are mainly processed in two ways: traditional frying at normal atmospheric pressure and vacuum frying. The nutrition of food is easy to destroy due to the high temperature of $160-180^{\circ} \mathrm{C}$. It generally leads to higher oil absorption that could be up to $50 \%$ of the total weight of the fried food (Pinthus et al., 1993), which particularly leads to several serious health problems, including coronary heart disease, cancer, diabetes and hypertension. By contrast, vacuum frying has many advantages attributed to low temperature and less oxygen in the frying process, such as (i) a reduction in oil deterioration; (ii) preservation of natural color and flavor; (iii) reduced oil content of fried products and decreased cancerogenic substances (Granda et al., 2004); and (iv) maintaining nutritional compounds (Silva \& Moreira, 2008). In recent years, with the increasing awareness of food safety, consumers are gradually inclined to eat low-fat or fat-free products. Thus, vacuum frying is an excellent and promising alternative technology.

With the increasing application of vacuum frying in breaded foods, it was found that vacuum fried breaded shrimps had light color, but were less attractive. Breaded foods are composed of the crust and interior food. However, its sophisticated batter formulation determines all the final quality performance of the breaded foods due to the functionality of its composition, concentration and characteristics. It was found that batter formulations have been developed with specific ingredients in recent studies, such as high amylose rice (Lee et al., 2013), sorghum flour modified with cassava starch (Onyango et al., 2011), tomato powder (Modzelewska-Kapituła, 2012) and mushroom powder (Kim et al., 2010). Thus, the ingredients of the new-type batter will also create a new breaded foods product with a high level of appeal of attributes.

The purple sweet potato (PSP) has attracted more and more attention from researchers in the last few years because of its natural purple color and high levels of nutritional value 
(Peng et al., 2013). Nowadays, PSP is cultivated widely in China as a resource of food and industrial material including beverages, natural colorants and rich polyphenol functional food ingredients (Liu et al., 2013; Truong et al., 2018). The purple sweet potato anthocyanins (PSPA) were found to have a remarkable range of effective activities such as anti-oxidation, antimutation and hepatoprotection. In addition, many studies have indicated that anthocyanins from PSP exhibited significant effects of alkalinity or acidity at different $\mathrm{pH}$ on the color of the PSP juice (Truong et al., 2019). Thus, this study uses purple sweet potato flour (PSPF) as the base material for the coating batter. Most importantly, the PSPA are sensitive to high temperature, which could be avoided during vacuum frying.

The objective of this study was to evaluate a batter system with PSPF, soy protein isolate (SPI) and xanthan gum for evaluating characteristics and quality. The batter system is even widely applied to other aquatic products and meat products with antioxidant activity.

\section{Materials and methods}

\subsection{Raw material}

The frozen headless shrimps (Litopenaeus vannamei) with average sizes of 70-90 shrimps/kg were purchased from Zhanjiang Guolian Aquatic Products Co., Ltd. (Zhanjiang, China) and kept frozen at $-20^{\circ} \mathrm{C}$ until use.

\subsection{Chemicals and other components used}

PSPF, wheat flour, SPI, salt, sugar, xanthan gum, sodium tripolyphosphate, anhydrous citric acid (food grade), bread crumbs and palm oil were purchased from Zhanjiang Keming Technology Co., Ltd. (Zhanjiang, China). Petroleum ether (boiling range $30-60^{\circ} \mathrm{C}$ ) used for the experiment was of analytical grade.

\subsection{Sample preparation}

The frozen headless vannamei shrimps were defrosted. Their shells were removed and the abdominal segments of the shrimps were cut to approximately $90 \%$ depth. Then, the shrimps were soaked in a saline solution for $40 \mathrm{~min}$. Finally, they were rinsed with cold water. Each sample was weighed before coating.

\subsection{Batter preparation}

The new batter systems consisted of PSPF and different ratios of SPI to xanthan gum (Table 1). All dry ingredients were thoroughly preblended and mixed with concentrations of $0.3 \%$ citric acid solution (Truong et al., 2019). A common batter system on the market was used as a control (Pan et al., 2015). To ensure thorough mixing, the batters were blended with an electric mixer at the lowest speed for $30 \mathrm{~s}$.

\subsection{Preparation of vacuum fried breaded shrimp}

Each sample was immersed in different batter formulas (Table 1) for $10 \mathrm{~s}$ and then coated with breadcrumbs. The breaded shrimps were stored in a refrigerator at $-18^{\circ} \mathrm{C}$ for $24 \mathrm{~h}$. Finally, the
Table 1. Compositions in batter flour mixture.

\begin{tabular}{ccccccccc}
\hline Sample & $\begin{array}{c}\text { PSPF } \\
(\%)\end{array}$ & $\begin{array}{c}\text { Wheat } \\
\text { flour } \\
(\%)\end{array}$ & $\begin{array}{c}\text { SPI } \\
(\%)\end{array}$ & $\begin{array}{c}\text { Xanthan } \\
\text { Gum } \\
(\%)\end{array}$ & $\begin{array}{c}\text { Salt } \\
(\%)\end{array}$ & $\begin{array}{c}\text { Sugar } \\
(\%)\end{array}$ & $\begin{array}{c}\text { Citric } \\
\text { acid } \\
(\%)\end{array}$ & $\begin{array}{c}\text { solid to } \\
\text { water } \\
(\mathrm{w} / \mathrm{v})\end{array}$ \\
\hline Control & $/$ & 92 & 8 & $/$ & 10 & 5 & $/$ & $1: 1.83$ \\
1 & 40 & $/$ & 50 & 10 & 10 & 5 & 0.3 & $1: 10$ \\
2 & 40 & $/$ & 40 & 20 & 10 & 5 & 0.3 & $1: 10$ \\
3 & 40 & $/$ & 30 & 30 & 10 & 5 & 0.3 & $1: 10$ \\
4 & 40 & $/$ & 20 & 40 & 10 & 5 & 0.3 & $1: 10$ \\
5 & 40 & $/$ & 10 & 50 & 10 & 5 & 0.3 & $1: 10$ \\
\hline
\end{tabular}

Control: The common batter system with wheat flour and soy protein isolate. 5:1, 2:1, 1:1, $1: 2,1: 5$ : The ratio of soy protein isolate to xanthan gum at contain content of purple sweet potato flour. The amount of sugar and salt added is the percentage of the total content of wheat flour and soy protein isolate. Citric acid solution (w/v).

frozen breaded shrimps were fried in a vacuum fryer (Haiyang Xinrui Food Equipment Co., Ltd., China) at the vacuum pressure of $65 \mathrm{kPa}$ and $95^{\circ} \mathrm{C}$ for $15 \mathrm{~min}$. Triplicate tests were taken for every experiment.

\subsection{Flow behaviors}

Flow behaviors of different batter systems were determined in a modular advanced rheometer (Rheometer HAAKE MARS III, Thermo Fisher Scientific Co., Ltd., NY, USA). The rheometer was equipped with plate geometry $\left(60 \mathrm{~mm}\right.$ diameter with a $2^{\circ}$ angle). The gap was set at $1.0 \mathrm{~mm}$. Triplicate scans were made (Lee et al., 2019).

\subsection{Coating pick-up}

Coating pick-up was analyzed in triplicate and it is measured by the method described by Salvador et al. (2005) using the following Equation 1:

Adhesion degree $=\frac{\text { weight of breaded shrimp } \text {-weight of breaded shrimp before coated }}{\text { weight of breaded shrimp }}$ (1)

\subsection{Color measurement}

The CIELAB color parameters [lightness $\left(L^{*}\right)$, green-red chromaticity $\left(a^{*}\right)$ and blue-yellow chromaticity $\left(b^{*}\right)$ ] of the crust sample color were measured in triplicate with a Color Difference Meter (NS810, 3NH Technology Co., Ltd., Shenzhen, China). Total color change $(\Delta E)$ is defined in the following Equation 2:

$$
\Delta \mathrm{E}=\sqrt{\mathrm{L}^{* 2}+\mathrm{a}^{* 2}+\mathrm{b}^{* 2}}
$$

\subsection{Moisture and oil content analysis}

The moisture contents of the samples were obtained on the basis of the weight difference in the dry state. The oil contents of the fried breaded shrimps were determined by the Soxhlet extraction method. The analysis was performed in triplicate.

\subsection{Texture analysis}

The crispness of crusts was evaluated with a texture analyzer (Food Technology Corporation, VA, USA). The maximum breaking force or hardness of the samples was measured with 
a $1000 \mathrm{~N}$ load cell. The samples were drilled with a cylindrical probe $(\mathrm{P} / 0.5)$, The maximum peak force represents the cutting force (in Newton, N) as a hardness value. Each analysis was performed using six samples.

\subsection{Determination of Total Anthocyanin Content (TAC)}

The total anthocyanin levels before and after frying were determined using a spectrophotometric method (Lees \& Francis, 1972). The samples obtained by different conditions were pulverized and extracted with $\mathrm{HCl}$-ethanol solution (95\% ethanol solution and $1.5 \mathrm{M} \mathrm{HCl}$ solution, $\mathrm{v} / \mathrm{v}$ : $85 / 15$ ) on a water bath kettle at $60^{\circ} \mathrm{C}$ for $2 \mathrm{~h}$ and combined power ultrasound for $40 \mathrm{~min}$. Then, the extraction was subjected to centrifugation and filtration. The absorbance of each dilution was measured at $535 \mathrm{~nm}$ against a distilled water blank using a spectrophotometer (UV757CRT; Yidian Analytical Instrument Co., Ltd., Shanghai, China). Anthocyanin content was calculated by the following Equation 3:

Anthocyanin content $(\mathrm{mg} / 100 \mathrm{~g})=\frac{100 \times \mathrm{E} \times \mathrm{V}}{98.28 \times \mathrm{M}}$

where $E$ is the absorbance at $535 \mathrm{~nm}, M$ is sample weight, $V$ is the dilution factor for the sample and 98.28 is the $1 \%$ anthocyanin extinction coefficient at $535 \mathrm{~nm}$.

\subsection{Antioxidant activity}

The DPPH (2,2-diphenyl-1-picrylhydrazyl) radical-scavenging ability of the PSP breaded shrimps extract was determined using a standard method (Park et al., 2012; Curi et al., 2019). Anthocyanin extract $(4.0 \mathrm{~mL})$ was mixed with $4.0 \mathrm{~mL}$ of DPPH $(0.0178 \mathrm{mM})$, measured quickly, then kept at room temperature for $30 \mathrm{~min}$ before measuring the absorbance at $517 \mathrm{~nm}$. Hydroxyl radical-scavenging ability of the anthocyanin extract was detected. Briefly, the anthocyanin extract $(1 \mathrm{~mL})$ was transferred to a colorimetric tube and mixed with $1 \mathrm{~mL}$ of $9 \mathrm{mM}$ salicylic acidethanol solution, $1 \mathrm{~mL}$ of $9 \mathrm{mM} \mathrm{FeSO}_{4}$ and $1 \mathrm{~mL}$ of $8.8 \mathrm{mmol} / \mathrm{L}$ $\mathrm{H}_{2} \mathrm{O}_{2}$. The mixture was put on a water bath kettle under $37^{\circ} \mathrm{C}$ for $30 \mathrm{~min}$. Finally, with distilled water as the background, the mixture was measured at $510 \mathrm{~nm}$ wavelength (Zhang et al., 2020).

\subsection{Statistical analysis}

The experimental results were mean \pm standard deviation $(n=3)$. The software JMP (Version 13, SAS Institute Inc., Cary, NC, USA) was utilized to perform analysis of variance (ANOVA). Duncan's multiple range tests were applied to determine the significant differences between control and treatments at the $95 \%$ confidence interval. Statistical analysis and processing were performed using the Origin 9.0 software (Microcal Software, Inc., Northampton, MA, USA).

\section{Results and discussion}

\subsection{Flow behaviors}

Batter viscosity within the batter systems significantly affects the flow behavior by the composition and proportion of the ingredients of the batter (Dogan et al., 2005). The change in the shear stress with shear rate for different batter systems can be seen in Figure 1 .

All investigated batter systems showed that the shear stress increased with increasing shear rate at low shear rate and showed marginal changes, thereafter indicating a typical non-Newtonian flow behavior; such findings are consistent with the previous study by Baixauli et al. (2003). The experimental results provided a good fit with a power-law model. The consistency and flow behavior indices for different batter systems are given in Table 2. The flow behavior index $(n)$ of each batter system was smaller than one revealing the shear thinning characteristics of the batters (Baixauli et al., 2003). The batter consistency index $(K)$ used as the viscosity of the dry components is related to water binding capacities in batter systems (Dogan et al., 2005). Compared with the control, the PSPF added batter system (PSPFB) was found to have higher viscosity. The higher viscosity of PSPFB manifested a higher amount of water held due to the high starch content of PSPF. In addition, SPI flour was enhanced in protein intensity and the gel effect (Sahin et al., 2005). Therefore, PSPFB has a higher viscosity and the batter viscosity increased when the ratio of SPI to xanthan gum decreased attributed to xanthan concentration as a thickener in foods.

\subsection{Coating pick-up}

Coating pick-up is an important index in the food industry, which is affected by food quality and process yield. In general, coating pick-up is 30-50\% (Hsia et al., 1992). It is directly related

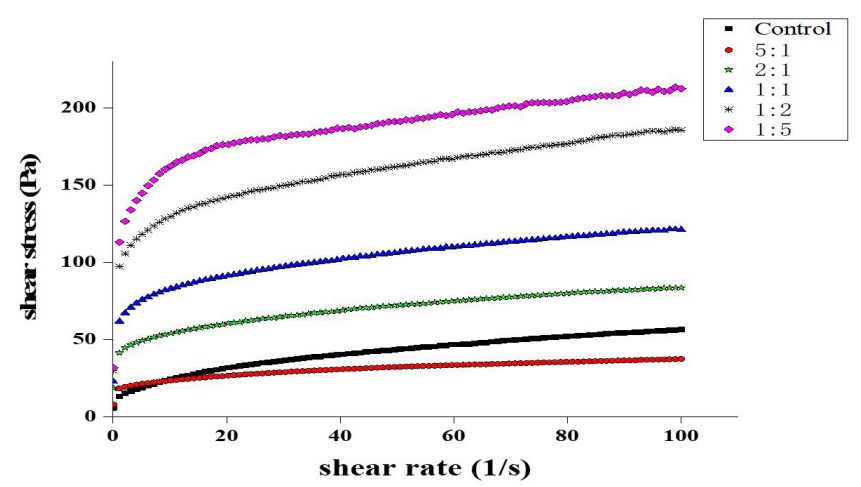

Figure 1. Change in the shear stress with shear rate for the different batter systems.

Table 2. Rheological properties of slurry with different batter systems.

\begin{tabular}{cccc}
\hline Batter system & $R^{2}$ & $K\left(\mathrm{Pas}^{\mathrm{n}}\right)$ & $n$ \\
\hline Control & $0.9948 \pm 0.0015^{\mathrm{a}}$ & $10.49 \pm 0.96^{\mathrm{f}}$ & $0.35 \pm 0.02^{\mathrm{a}}$ \\
$05: 01$ & $0.9767 \pm 0.0051^{\mathrm{ab}}$ & $14.63 \pm 0.74^{\mathrm{e}}$ & $0.20 \pm 0.00^{\mathrm{b}}$ \\
$02: 01$ & $0.9751 \pm 0.0061^{\mathrm{ab}}$ & $34.89 \pm 1.19^{\mathrm{d}}$ & $0.18 \pm 0.00^{\mathrm{bc}}$ \\
$01: 01$ & $0.9572 \pm 0.0018^{\mathrm{ab}}$ & $51.39 \pm 0.77^{\mathrm{c}}$ & $0.18 \pm 0.10^{\mathrm{bc}}$ \\
$01: 02$ & $0.9247 \pm 0.0041^{\mathrm{b}}$ & $78.78 \pm 1.62^{\mathrm{b}}$ & $0.18 \pm 0.01^{\mathrm{bc}}$ \\
$01: 05$ & $0.8059 \pm 0.0528^{\mathrm{c}}$ & $98.13 \pm 0.52^{\mathrm{a}}$ & $0.17 \pm 0.01^{\mathrm{c}}$ \\
\hline
\end{tabular}

Values are expressed as the mean $\pm \mathrm{SD}(n=3)$. Mean value in the same column with different superscripts varies significantly $(p<.05) . R 2$ : The regression coefficients of power law model. $K$ : The batter consistency index. $n$ : The flow behavior index. 
to batter viscosity. The coating pick-up of the different batter systems is shown in Figure 2.

The highest pick-up measurement was found in the case of samples that contain PSPFB, which is consistent with its higher apparent viscosity. The present results agree with other findings, which showed a relationship between coating pick-up and the consistency index $(K)$ of batter systems (Amboon et al., 2012). What is more, these findings observed higher coating pick-up for higher batter viscosity (Dogan et al., 2005; Sanz et al., 2008). Compared with the control group, there are no significant differences with the ratio of 5:1 and 2:1 for SPI to xanthan gum of PSPFB. In addition, the lowest coating pick-up was found in samples that contain the ratio of 1:5 of SPI to xanthan gum of PSPFB. Obviously, coating pick-up was decreased with the highest batter viscosity due to the low thickening capability (Adedeji \& Ngadi, 2011).

\subsection{Color parameters}

Color is a crucial quality factor affecting customers' perception of fried products (Dueik et al., 2010). The different batter systems would influence the color of the breaded shrimps. The color changes of the vacuum fried breaded shrimps were measured by analyzing the color parameters, namely, $L^{*}, a^{*}, b^{*}$ and $\Delta E$ (Qiu et al., 2018). The effects of the different batter systems on the color of the breaded shrimps are presented in Table 3. $L^{*}$ is one of the most important quality parameters for frying foods. It is

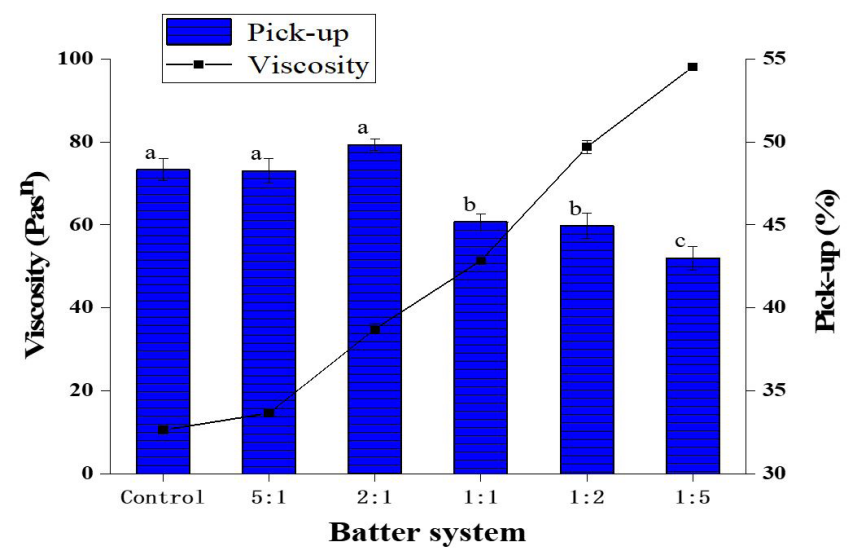

Figure 2. The effect of different batter systems on the coating pick-up of breaded shrimp at different viscosities. Mean value with different superscripts varies significantly $(p<0.05)$.

Table 3. Color parameters of vacuum breaded shrimp.

\begin{tabular}{ccccc}
\hline $\begin{array}{c}\text { Batter } \\
\text { system }\end{array}$ & $L^{*}$ & $a^{*}$ & $b^{*}$ & $\Delta E$ \\
\hline Control & $50.96 \pm 0.47^{\mathrm{a}}$ & $0.21 \pm 0.03^{\mathrm{d}}$ & $5.73 \pm 0.02^{\mathrm{a}}$ & $51.28 \pm 0.47^{\mathrm{a}}$ \\
$05: 01$ & $47.34 \pm 0.24^{\mathrm{b}}$ & $3.34 \pm 0.14^{\mathrm{a}}$ & $0.73 \pm 0.03^{\mathrm{d}}$ & $47.45 \pm 0.27^{\mathrm{b}}$ \\
$02: 01$ & $46.43 \pm 0.37^{\mathrm{c}}$ & $3.07 \pm 0.23^{\mathrm{ab}}$ & $0.52 \pm 0.06^{\mathrm{d}}$ & $46.53 \pm 0.37^{\mathrm{bc}}$ \\
$01: 01$ & $46.28 \pm 0.65^{\mathrm{c}}$ & $2.96 \pm 0.10^{\mathrm{ab}}$ & $1.15 \pm 0.12^{\mathrm{cd}}$ & $46.40 \pm 0.64^{\mathrm{bc}}$ \\
$01: 02$ & $45.40 \pm 0.53^{\mathrm{d}}$ & $2.71 \pm 0.23^{\mathrm{bc}}$ & $1.66 \pm 0.51^{\mathrm{bc}}$ & $45.55 \pm 0.02^{\mathrm{b}}$ \\
$01: 05$ & $45.45 \pm 0.03^{\mathrm{d}}$ & $2.49 \pm 0.09^{\mathrm{c}}$ & $1.94 \pm 0.09^{\mathrm{b}}$ & $45.50 \pm 0.53^{\mathrm{c}}$ \\
\hline
\end{tabular}

Values are expressed as the mean $\pm \mathrm{SD}(n=3)$. Mean value in the same column with different superscripts varies significantly $(p<0.05) . \Delta E$ : Total color change. known that a higher value of $L^{\star}$ represents a brighter appearance. It can be observed in Table 2 that the $L^{*}$ value significantly $(p<.05)$ decreased for the vacuum fried shrimps with PSPFB compared with the corresponding values in the control batter system of breaded shrimps. In contrast, the color of the vacuum fried shrimps with PSPFB had higher $a^{*}$ and lower $b^{*}$ values. It was reported that there is a relationship between the color and the anthocyanin content of PSPF (Liu et al., 2014; Oliveira et al., 2020). The natural color is unstable and vulnerable to a lot of factors (e.g., $\mathrm{pH}$, metal ions, temperature, light and oxygen) (Szadziniska et al., 2017). It was found that chemical changes of oil and materials during frying processes affected the color parameters of fried food (Gertz et al., 2017). Considering the total color change in vacuum fried shrimps with PSPFB, this result reflects the slight effect of the ratio of SPI to xanthan gum of PSPFB on the color of the vacuum fried breaded shrimps. Conclusively, the PSPFB helps achieve better color attributes of fried products.

\subsection{Moisture and oil content}

Moisture content and oil content are significant quality factors of fried breaded shrimps. Figure 3 shows the moisture and oil content of the breaded shrimps in different batter systems fried under vacuum conditions.

The batter system significantly affected the moisture and oil content of the breaded shrimps $(p<0.05)$. Compared with the control group, PSPFB of breaded shrimps significantly presented high moisture content and low oil content. This result may also be due to higher SPI and xanthan gum content with more water binding capacity in the PSPFB. Considering the total change of moisture and oil content, there was a negative link between moisture content and oil content (Sahin et al., 2005). In addition, the moisture and oil content of PSPFB were changed due to the ratio of SPI to xanthan gum. The ratio of 2:1 for SPI to xanthan gum provided the highest moisture content and the lowest oil content due to the SPI and xanthan gum providing the best film-forming ability with the highest binding capacity (Adedeji et al., 20011).

\subsection{Texture analysis}

Texture is an important characteristic for the acceptability of fried food. In this study, the textural properties of the breaded

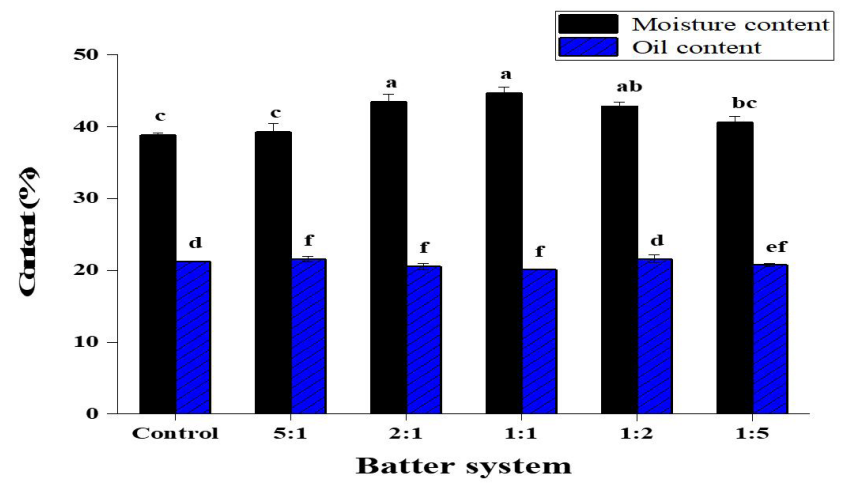

Figure 3. The effect of different batter systems on the moisture and oil content of breaded shrimp. Mean value with different superscripts varies significantly $(p<0.05)$. 
shrimps were measured in terms of breaking force. As an important quality index of frying products, the breaking force of the fried products can be used as an indicator of crispness and the lower the breaking force, the higher the crispness (Sinthusamran \& Benjakul, 2015). The breaking force of the vacuum fried breaded shrimps with different batter systems is shown in Figure 4. As is shown in Figure 4, the breaking force decreased compared with the control. In general,the PSPF batter system was viscous enough to keep the gas within the system. The same study reported that the xanthan gum induced the highest porosity in the product due to the greater ability of this gum to retain gas (Varela \& Fiszman, 2011). Conclusively, the ratio of 2:1 for SPI to xanthan gum in PSPFB provided the lowest breaking force with the highest crispness of vacuum fried breaded shrimps.

\subsection{Total Anthocyanin Content (TAC)}

PSPs are rich sources of anthocyanins with desirable colors and nutritional benefits and would be an ideal ingredient for preparing PSPFB for vacuum fried breaded shrimps with natural color (Giri et al., 2019). The anthocyanin degrades during the frying process, which has a dramatic impact on color quality and also affects nutritional properties (Wrolstad et al., 2005). The total anthocyanin content with PSPFB of vacuum fried breaded

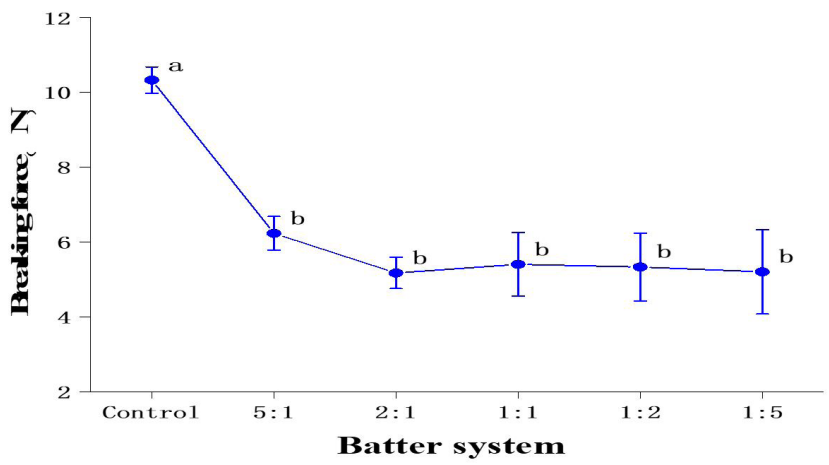

Figure 4. The effect of different batter systems on the break force of breaded shrimp. Mean value with different superscripts varies significantly $(p<0.05)$.

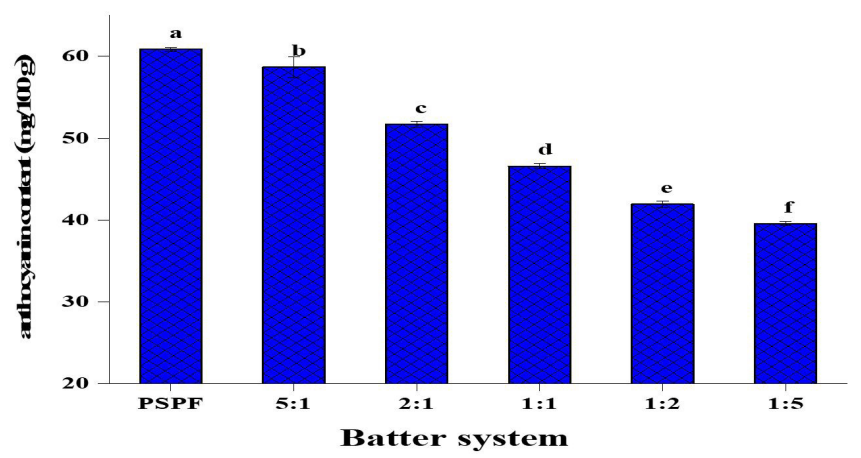

Figure 5. The effect of different batter systems on the anthocyanin content of breaded shrimp. Mean value with different superscripts varies significantly $(p<0.05)$. shrimps is shown in Figure 5. Compared with PSPF itself, the higher surface temperature of breaded shrimps during the vacuum frying process would cause the reduction of anthocyanin levels. Anthocyanin from PSPF was affected by processing conditions and temperature (Liu et al., 2012). In addition, the total anthocyanin content of vacuum fried breaded shrimps with PSPFB was reduced when the ratio of SPI to xanthan gum was decreased. This might be due to anthocyanin being a type of small-molecule active substance with strong protein affinity which can form a variety of crosslinking proteins with stiff stability (Mulaudzi et al., 2012). It can be concluded that vacuum frying could decrease the decomposition of the total anthocyanin level of fried products.

\subsection{Antioxidant activity}

The effects of vacuum fried treatment conditions on the DPPH and hydroxyl $(\bullet \mathrm{OH})$ radical-scavenging activities of the PSP cultivars are presented in Figure 6. The DPPH and $\bullet \mathrm{OH}$ radicals are used widely to evaluate the free-radical-scavenging activities of anthocyanin in PSPF (Netzel et al., 2003). As shown in Figure 6, significant differences in the aspects of DPPH and - OH assay were noted among different samples $(p<0.05)$. DPPH and $\bullet \mathrm{OH}$ assay of the control sample was lowest at 0 and $4.56 \%$, respectively. In the DPPH and $\bullet \mathrm{OH}$ test, PSPF without any treatment showed the highest free-radical-scavenging ability, followed by those of vacuum fried breaded shrimps with PSPFB (PSPFBS). That is because the anthocyanin content decreases during frying. In a word, the anthocyanin in PSPFBS after vacuum frying still has antioxidant activity.

\section{Conclusion}

The batter system with PSPF, SPI and xanthan gum significantly affected rheological properties, coating pick-up, color, moisture content, oil content, texture, anthocyanin content and antioxidant activity. At constant PSPF content in the batter system, the result showed that the ratio of 2:1 for SPI to xanthan gum had appropriate rheological properties with the

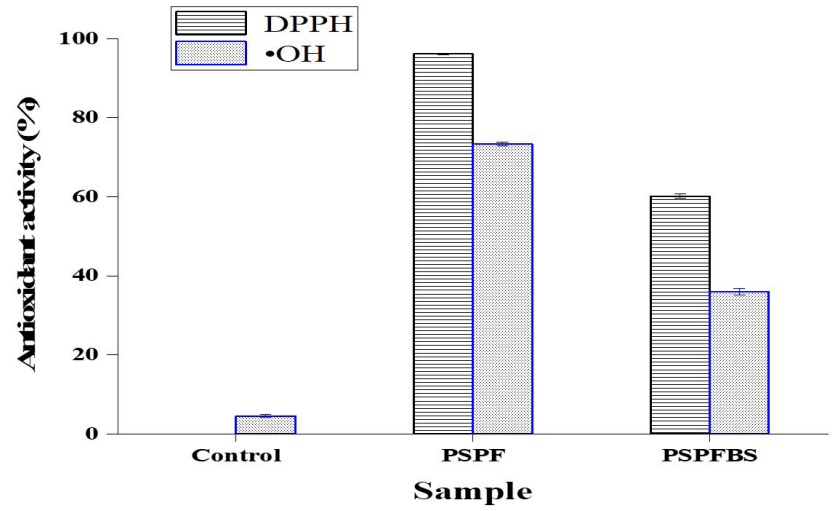

Figure 6. The antioxidant activity of different samples. Control: The vacuum fried breaded shrimps in the control batter system with wheat flour and soy protein isolate. PSPF: Purple sweet potato flour. PSPFBS: The vacuum fried breaded shrimps in purple batter system with a ratio 2:1 for soy protein isolate to xanthan gum at contain content of purple sweet potato flour. 
highest coating pick-up value. Meanwhile, vacuum fried shrimps had a more attractive purple, less oil content, higher moisture content and retained higher anthocyanin content. What is more, vacuum fried PSPF breaded shrimps retain antioxidant activity. Therefore, the batter system with PSPF, SPI and xanthan gum is a promising coating material and can be recommended to be used for other aquatic products and meat products, which are processed using vacuum frying, such as pork steak, chicken nuggets and fish fingers.

\section{References}

Adedeji, A. A., \& Ngadi, M. O. (2011). Microstructural properties of deep fat fried chicken nuggets coated with different batter formulation. International Journal of Food Properties, 14(1), 68-83. http://dx.doi. org/10.1080/10942910903131423.

Amboon, W., Tulyathan, V., \& Tattiyakul, J. (2012). Effect of hydroxypropyl methylcellulose on rheological properties, coating pickup, and oil content of rice flour-based batters. Food and Bioprocess Technology, 5(2), 601-608. http://dx.doi.org/10.1007/s11947-010-0327-3.

Baixauli, R., Sanz, T., Salvador, A., \& Fiszman, S. M. (2003). Effect of the addition of dextrin or dried egg on the rheological and textural properties of batters for fried foods. Food Hydrocolloids, 17(3), 305310. http://dx.doi.org/10.1016/S0268-005X(02)00091-7.

Curi, P. N., Salgado, D. L., Mendonça, K., Pio, R., Ferreira, J. L. G., \& Souza, V. R. (2019). Influence of microwave processing on the bioactive compounds, antioxidant activity and sensory acceptance of blackberry jelly. Food Science and Technology, 39(Suppl. 2), 386391. http://dx.doi.org/10.1590/fst.18618.

Dogan, S. F., Sahin, S., \& Sumnu, G. (2005). Effects of soy and rice flour addition on batter rheology and quality of deep fat-fried chicken nuggets. Journal of Food Engineering, 71(1), 127-132. http://dx.doi. org/10.1016/j.jfoodeng.2004.10.028.

Dueik, V., Robert, P., \& Bouchon, P. (2010). Vacuum frying reduces oil uptake and improves the quality parameters of carrot crisps. Food Chemistry, 119(3), 1143-1149. http://dx.doi.org/10.1016/j. foodchem.2009.08.027.

Gertz, C., Aladedunye, F., \& Matthäus, B. (2017). A new analytical and statistical approach to predict the sensory properties of deep frying fats and oils to determine the point of discard during processing. European Journal of Lipid Science and Technology, 119(11), 1600393. http://dx.doi.org/10.1002/ejlt.201600393.

Giri, N. A., Pradeepika, C., \& Sajeev, M. S. (2019). Process optimization by response surface methodology and quality attributes of orange fleshed sweet potato (Ipomoea batatas L.) vacuum fried chips. Journal of Food Measurement and Characterization, 13(3), 2367-2376. http:// dx.doi.org/10.1007/s11694-019-00156-x.

Granda, C., Moreira, R., \& Tichy, S. (2004). Reduction of acrylamide formation in potato chips by low-temperature vacuum frying. Journal of Food Science, 69(8), e405-e411. http://dx.doi. org/10.1111/j.1365-2621.2004.tb09903.x.

Hsia, H. Y., Smith, D. M., \& Steffe, J. F. (1992). Rheological properties and adhesion characteristics of flour-based batters for chicken nuggets as affected by three hydrocolloids. Journal of Food Science, 57(1), 16-18. http://dx.doi.org/10.1111/j.1365-2621.1992.tb05414.x.

Kim, J., Lim, J., Bae, I. Y., Park, H. G., Lee, H. G., \& Lee, S. (2010). Particle size effect of lentinus edodes mushroom (chamsong-1) powder on the physicochemical, rheological, and oil-resisting properties of frying batters. Journal of Texture Studies, 41(3), 381-395. http:// dx.doi.org/10.1111/j.1745-4603.2010.00231.x.
Lee, S. M., Yoo, J., Inglett, G. E., \& Lee, S. (2013). Particle size fractionation of high-amylose rice (Goami 2) flour as an oil barrier in a battercoated fried system. Food Biological Processing Technology, 6(3), 726-733. http://dx.doi.org/10.1007/s11947-011-0721-5.

Lee, Y., Dias-Morse, P. N., \& Meullenet, J. F. (2019). Effect of rice variety and milling fraction on the starch gelatinization and rheological properties of rice milk. Food Science and Technology, 39(4), 10471051. http://dx.doi.org/10.1590/fst.17118.

Lees, D. H., \& Francis, F. J. (1972). Standardization of pigment analyses in cranberries. Hort, 7(1), 66-74. .

Liu, P., Zhang, M., \& Mujumdar, A. S. (2012). Comparison of three microwave-assisted drying methods on the physiochemical, nutritional and sensory qualities of re-structured purple-fleshed sweet potato granules. International Journal of Food Science \& Technology, 47(1), 141-147. http://dx.doi.org/10.1111/j.1365-2621.2011.02819.x.

Liu, P., Zhang, M., \& Mujumdar, A. S. (2014). Purple-fleshed sweet potato cubes drying in a microwave-assisted spouted bed dryer. Drying Technology, 32(15), 1865-1871. http://dx.doi.org/10.1080/ 07373937.2014.953174.

Liu, X., Mu, T., Sun, H., Zhang, M., \& Chen, J. (2013). Optimisation of aqueous two-phase extraction of anthocyanins from purple sweet potatoes by response surface methodology. Food Chemistry, 141(3), 3034-3041. http://dx.doi.org/10.1016/j.foodchem.2013.05.119. PMid:23871056.

Modzelewska-Kapituła, M. (2012). Effects of tomato powder on color, lipid oxidation and sensory properties of comminuted meat products. Journal of Food Quality, 35(5), 323-330. http://dx.doi. org/10.1111/j.1745-4557.2012.00457.x.

Mulaudzi, R. B., Ndhlala, A. R., Kulkarni, M. G., \& Van Staden, J. (2012). Pharmacological properties and protein binding capacity of phenolic extracts of some venda medicinal plants used against cough and fever. Journal of Ethnopharmacology, 143(1), 185-193. http://dx.doi.org/10.1016/j.jep.2012.06.022. PMid:22732728.

Netzel, M., Strass, G., Bitsch, I., Könitz, R., Christmann, M., \& Bitsch, R. (2003). Effect of grape processing on selected antioxidant phenolics in red wine. Journal of Food Engineering, 56(2-3), 223-228. http:// dx.doi.org/10.1016/S0260-8774(02)00256-X.

Oliveira, A. R., Ribeiro, A. E. C., Oliveira, É. R., Garcia, M. C., Soares, M. S. Jr., \& Caliari, M. (2020). Structural and physicochemical properties of freeze-dried açaí pulp (Euterpe oleracea Mart.). Food Science and Technology, 40(2), 282-289. http://dx.doi.org/10.1590/fst.34818.

Onyango, C., Mutungi, C., Unbehend, G., \& Lindhauer, G. M. (2011). Rheological and textural properties of sorghum-based formulations modified with variable amounts of native or pregelatinised cassava starch. Lebensmittel-Wissenschaft + Technologie, 44(3), 687-693. http://dx.doi.org/10.1016/j.lwt.2010.08.019.

Pan, G., Ji, H., Liu, S., \& He, X. (2015). Vacuum frying of breaded shrimps. Lebensmittel-Wissenschaft + Technologie, 62(1), 734-739. http://dx.doi.org/10.1016/j.lwt.2015.01.007.

Park, J. H., Jeon, G. I., Kim, J. M., \& Park, E. (2012). Antioxidant activity and anti proliferative action of methanol extracts of 4 different colored bell peppers (Capsicum annuum L.). Food Science and Biotechnology, 21(2), 543-550. http://dx.doi.org/10.1007/s10068-012-0069-2.

Peng, Z., Li, J., Guan, Y., \& Zhao, G. (2013). Effect of carriers on physicochemical properties, antioxidant activities and biological components of spray-dried purple sweet potato flours. LebensmittelWissenschaft + Technologie, 51(1), 348-355. http://dx.doi.org/10.1016/j. lwt.2012.09.022. 
Pinthus, E. J., Weinberg, P., \& Saguy, I. S. (1993). Criterion for oil uptake during deep-fat frying. Journal of Food Science, 58(1), 204-205. https://doi.org/10.1111/j.1365-2621.1993.tb03245.x.

Qiu, L., Zhang, M., Wang, Y., \& Bhandari, B. (2018). Effects of ultrasound pre-treatments on the quality of fried sweet potato (ipomea batatas) chips during microwave-assisted vacuum frying. Journal of Food Process Engineering, 41(8), e12879. http://dx.doi.org/10.1111/jfpe.12879.

Sahin, S., Sumnu, G., \& Altunakar, B. (2005). Effect of batters containing different gum types on the quality of deep-fat fried chicken nuggets. Journal of the Science of Food and Agriculture, 85(14), 2375-2379. http://dx.doi.org/10.1002/jsfa.2258.

Salvador, A., Sanz, T., \& Fiszman, S. M. (2005). Effect of the addition of different ingredients on the characteristics of a batter coating for fried seafood prepared without a pre-frying step. Food Hydrocolloids, 19(4), 703-708. http://dx.doi.org/10.1016/j.foodhyd.2004.07.003.

Sanz, T., Salvador, A., \& Fiszman, S. M. (2008). Performance of three different types of resistant starch in fried battered food. European Food Research and Technology, 227(1), 21-27. http://dx.doi.org/10.1007/ s00217-007-0687-8.

Silva, P., \& Moreira, R. (2008). Vacuum frying of high-quality fruit and vegetable based snacks. Lebensmittel-Wissenschaft + Technologie, 41(10), 1758-1767. http://dx.doi.org/10.1016/j.lwt.2008.01.016.

Sinthusamran, S., \& Benjakul, S. (2015). Effect of drying and frying conditions on physical and chemical characteristics of fish maw from swimbladder of seabass (Lates calcarifer). Journal of the Science of Food and Agriculture, 95(15), 3195-3203. http://dx.doi.org/10.1002/ jsfa.7059. PMid:25546167.
Surojanametakul, V., Karnasuta, S., \& Satmalee, P. (2020). Effect of oil type and batter ingredients on the properties of deep-frying flakes. Food Science and Technology. In press. http://dx.doi.org/10.1590/ fst.32919.

Truong, A. N., Thor, Y., Harris, G. K., Simunovic, J., \& Truong, V. D. (2019). Acid inhibition on polyphenol oxidase and peroxidase in processing of anthocyanin-rich juice and co-product recovery from purple-fleshed sweet potatoes. Journal of Food Science, 84(7), 17301736. http://dx.doi.org/10.1111/1750-3841.14664. PMid:31218701.

Truong, V. D., Avula, R. Y., Pecota, K. V., \& Yencho, G. C. (2018). Sweet potato production, processing, and nutritional quality. In $\mathrm{M}$. Siddiq \& M. A. Uebersax (Eds.), Handbook of vegetables and vegetable processing (2nd ed., pp. 811-838). New York: John Wiley \& Sons. http://dx.doi.org/10.1002/9781119098935.ch35.

Varela, P., \& Fiszman, S. M. (2011). Hydrocolloids in fried foods. a review. Food Hydrocolloids, 25(8), 1801-1812. http://dx.doi.org/10.1016/j. foodhyd.2011.01.016.

Wrolstad, R. E., Durst, R. W., \& Lee, J. (2005). Tracking color and pigment changes in anthocyanin products. Trends in Food Science \& Technology, 16(9), 423-428. http://dx.doi.org/10.1016/j.tifs.2005.03.019.

Zhang, L., Liao, L., Qiao, Y., Wang, C., Shi, D., An, K., \& Hu, J. (2020). Effects of ultrahigh pressure and ultrasound pre-treatments on properties of strawberry chips prepared by vacuum-freeze drying. Food Chemistry, 303, 125386. http://dx.doi.org/10.1016/j. foodchem.2019.125386. PMid:31473454. 